\title{
Scanning electron microscopic study of ovary and oviduct of crossbred dairy cows with ovarian hypoplasia
}

\author{
V.R. Annie ${ }^{1}$, K.M. Lucy², N. Ashok ${ }^{3}$, S. Maya ${ }^{4}$, \\ M.H. Hiron ${ }^{5}$ and T. Sathu ${ }^{6}$ \\ Department of Veterinary Anatomy and Histology \\ College of Veterinary and Animal Sciences, \\ Mannuthy, Thrissur, Kerala, 680651. \\ Kerala Veterinary and Animal Sciences University, India.
}

Citation: Annie, V.R., Lucy, K.M., Ashok, N., Maya, S., Hiron, M.H. and Sathu, T. 2021. Scanning electron microscopy of ovary and oviduct of crossbred dairy cows with ovarian hypoplasia. J. Vet. Anim. Sci. 52(2): 187-190. DOI: https://doi.org/10.51966/jvas.2021.52.2.187-190

\begin{abstract}
Hypoplasia of ovary is one of the major causes of infertility in dairy cattle, which is characterized by absence of oestrus cycle, affecting livestock productivity and economics to a great extent. This study was conducted on the female genitalia collected from 100 dairy cows/heifers from the Meat Technology Unit, Mannuthy which included six animals culled on account of factors other than infertility with normal genitalia (control group) and remaining animals with a known history of infertility. Two animals of 22 months and 24 months of age showed bilateral ovarian hypoplasia. The history revealed that the animals were healthy, but had not shown oestrus. Grossly ovaries of the first animal appeared as pink-coloured, small, wrinkled, flattened, elongated structures without any follicles or CL. Second animal showed inactive, small, flat, streak-like left ovary without any cyclical structures. But the right ovary showed a single large corpus haemorrhagicum on the caudal end. Then ovarian tissue was fixed in 2 percent gluteraldehyde in $0.1 \mathrm{M}$ phosphate buffer at $\mathrm{pH}$ 7.3. Under scanning electron microscopy, the ovary exhibited an uneven surface with clefts and grooves. The surface cells lost their normal appearance without any microvilli. Large round smooth germ cells were also observed on the ovarian surface. In the oviduct, the mucosa was lined by nonciliated cells having rounded surface interspersed among shrunken cells. The epithelial cell surface was covered with bulbous processes. Ciliated cells were not observed in the present study. Ovarian abnormality is reported to be the main cause of altered morphology of the surface epithelial cells and change in the ultrastructure of oviductal mucosa.
\end{abstract}

\footnotetext{
* Part of PhD thesis submitted to Kerala Veterinary and Animal Sciences University,

Pookode, Wayanad, Kerala

1. PhD Scholar

2. Professor and Controller of Examinations, Directorate of Academics and Research, KVASU Corresponding author: Ph: 9446408861 email id: lucy@kvasu.ac.in

3. Registrar, KVASU

4. Professor and Head

5. Assistant Professor, Department of Animal Reproduction Gynaecology and Obstetrics

6. Assistant Professor, Department of Livestock Products Technology
}

Copyright: ( 2021 V.R. Annie et al. This is an open access article distributed under the terms of the Creative Commons Attribution 4.0 International License (http://creativecommons.org/licenses/by/4.0/), which permits unrestricted use, distribution, and reproduction in any medium, provided the original author and source are credited. 
Key words: Ovarian hypoplasia, Scanning Electron Microscopy, Dairy cows

Infertility is one of the major problems confronting the dairy industry and is a frequent reason for culling. Features like anatomical defects, nutritional factors, improper herd management, hormonal disturbances and diseases affecting the reproductive system may disturb the balance and thus influence fertility. Among factors influencing the reproductive performance, anatomical abnormalities in the ovary are of great importance. Better understanding of the cellular differences and functions that occur in the female reproductive tract in domestic animals is required for the proper diagnosis and treatment of reproductive problems. Therefore, this work was undertaken to study the ultrastructural details of the ovary and oviduct of animals with bilateral ovarian hypoplasia and correlate it with functional processes.

The present study was conducted on the female genitalia collected from 100 dairy cows/heifers from the Meat Technology Unit, Mannuthy. This included six animals culled on account of factors other than infertility with normal reproductive system (control group) and the remaining animals with a known history of infertility. Two animals of 22 months and 24 months of age showed bilateral ovarian hypoplasia condition. The history revealed that the animals were healthy, but had not shown oestrus. After recording the morphological and morphometrical features of the genitalia, the ovaries and oviducts were separated and washed in normal saline and the adipose tissue surrounding the ovaries was removed by careful dissection. The fixation of tissues was carried out in 2.5 per cent gluteraldehyde prepared in $0.1 \mathrm{M}$ phosphate buffer at $4{ }^{\circ} \mathrm{C}$. After fixation, the tissues were washed in $0.1 \mathrm{M}$ PBS for $10 \mathrm{~min}$ each. The samples were dehydrated through serial dilutions of ethanol $(50 \%, 60 \%$, $70 \%, 80 \%, 90 \%$ and $100 \%$ ) for 45 min each. The samples were air dried and mounted on sample stub with double sided carbon adhesive tape. The samples were sputter coated with a thin layer of gold for making it conductive using an automated sputter coater. Finally, the tissues were analysed using scanning electron microscope (Hitachi $3000 \mathrm{~N}$ ) at an accelerated voltage of $15 \mathrm{kV}$ and microphotographs were taken.

Among the 100 animals under study, two animals of 22 months and 24 months

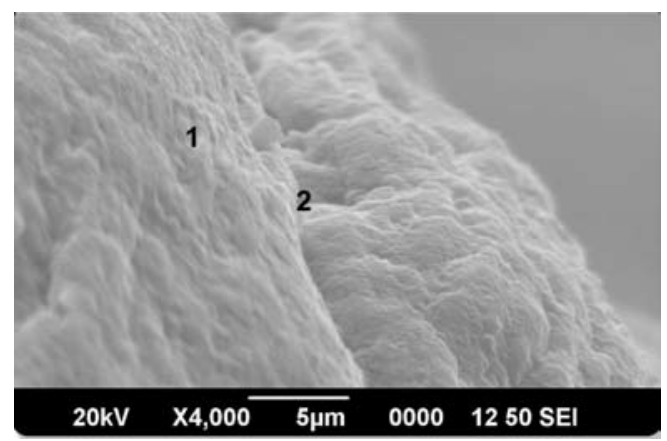

Fig. 1. SEM image of squamous epithelial cells of the ovary. SEM $\times 4000$

1. Squamous epithelial cells

2. Ridges

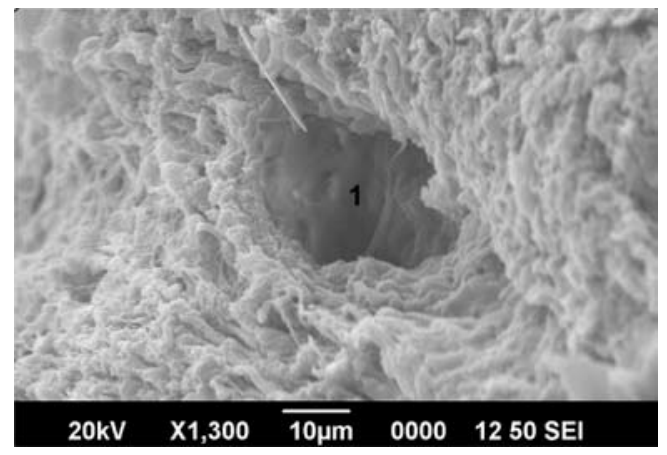

Fig. 2. SEM image of the surface of the ovary. SEM x 1300

1. Epithelial Cleft

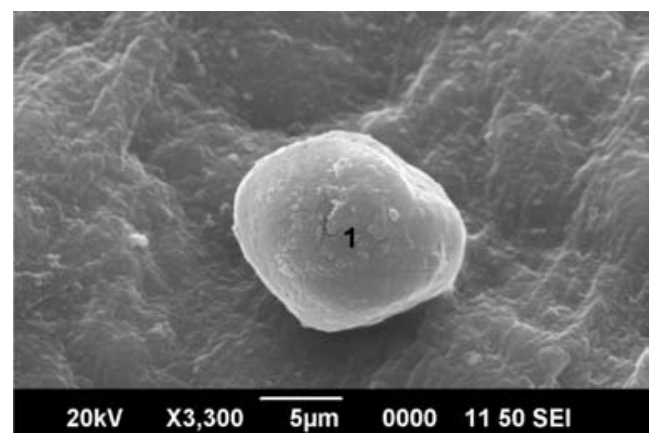

Fig. 3. SEM image of germ cells. SEM $x$ 3300

1. Germ cells 


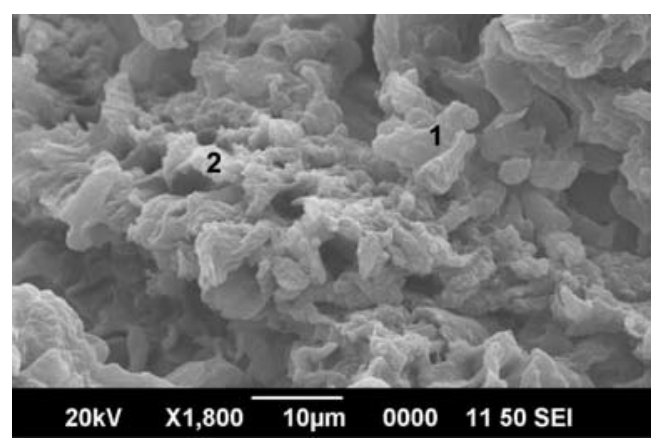

Fig. 4. SEM image of mucosal folds of the oviduct. SEM x 1800

1. Non - ciliated epithelial cells

2. Ridges

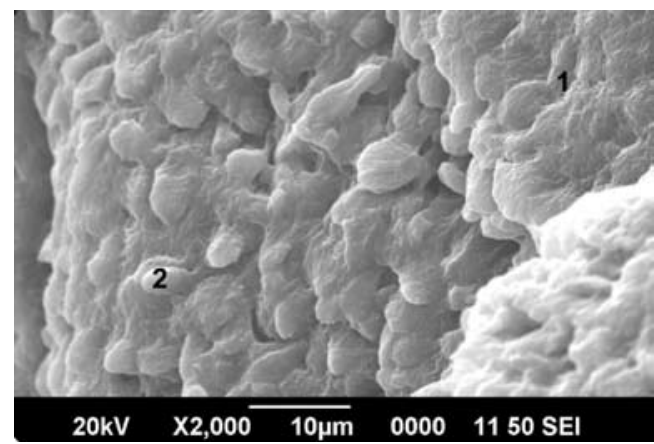

Fig. 5. SEM image of bulbous processes on the surface of non-ciliated cells of oviduct. SEM x 2000

1. Non - ciliated epithelial cells

2. Bulbous process

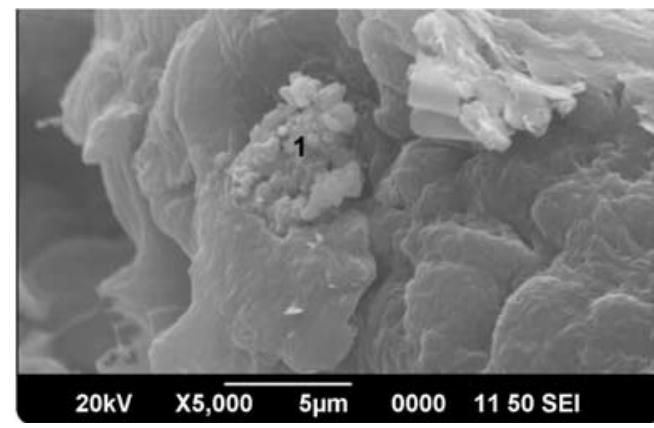

Fig. 6. SEM image of secretory material of the oviductal epithelium. SEM x 5000

1. Secretory material

of age showed bilateral ovarian hypoplasia condition constituting an incidence rate of two per cent. Ovaries of the first animal appeared as pink-coloured, small, wrinkled, flattened, elongated structures without any follicles or corpora lutea. Morphological examination of the ovaries of the second animal showed inactive, small, flat, streak-like left ovary without any cyclical structures. But the right ovary showed a single large corpus haemorrhagicum on the caudal end. No follicular structures could be located grossly. These animals did not exhibit any oestrus signs thereby being completely infertile and was considered as bilateral ovarian hypoplasia.

In scanning electron microscopy (SEM), the ovary was characterized by an uneven surface with clefts and grooves (Fig. 1) The surface cells lost their normal appearance and were arranged more closely. This is comparable to the findings of Hartanti et al. (2019) who stated that the surface epithelium of the adult and foetal ovary was dynamic which altered by repair of the tunica albugenia and surface epithelium or during cell death. Gillett et al. (1991) explained two types of epithelial cells on the surface of ovary in human and named as Type A and Type B cells. Type A cells were cuboidal, whereas Type $B$ cells were flat squamous type with broad and flat apices.

In between the tightly packed epithelium some invaginations/clefts could be located (Fig. 2). Hartanti et al. (2019) also observed clefts and grooves in the surface of the developing foetal ovary who related this as the opening of ovigerous cords to the surface of ovary. The stroma originating from the mesonephros extended laterally below the ovarian surface. At this point, some germ cells were trapped on the surface. Such germ cells which were larger than the surface epithelial cells could be observed on the ovarian surface in the present study also which was characterized by round shape with smooth surfaced appearance (Fig. 3). The overall features of hypoplastic ovary resembled the foetal ovary in the present study which suggests that the development of the ovary might have arrested in the foetal stage that led to the condition of ovarian hypoplasia.

The mucosa of oviduct was thrown into folds and lined by non-ciliated cells (Fig. 4). The surface of these cells was seen as rounded in appearance and some cells had a shrunken appearance also. The epithelial cell 
surface was covered with bulbous processes which were uniform in size and elliptical in shape without any microvilli (Fig. 5). These are in accordance with the observations of Abe and Oikawa (1993) in bovines, Kumar et al. (2008) in buffalo cows and Tienthai et al. (2009) in Thai swamp buffalo cows who also found numerous bulbous processes of non-ciliated cells in the epithelium of oviduct during the luteal phase. Between the mucosal folds, secretory material was observed as secretory droplets (Fig. 6). Similarly, Pathak et al. (2012) also noticed large amount of secretory materials on the surface of secretory cells during the luteal phase in ovine oviducts. Tienthai and Sajjarengpong (2007) could observe thin, smooth and uniform cilia for oviductal epithelium which were absent in the present study. This could be correlated to the functionally inactive ovary.

\section{Acknowledgement}

The authors are grateful to Department of Animal Husbandry, Government of Kerala, STIC, Cochin and Kerala Veterinary and Animal Sciences University for granting financial support and for providing necessary facilities needed for carrying out the research.

\section{References}

Abe, H. and Oikawa, T. 1993. Observations by scanning electron microscopy of oviductal epithelial cells from cows at follicular and luteal phases. Anat. Rec. 235: 399-410.
Gillett, W.R., Mitchell, A. and Hurst, P.R. 1991. A scanning electron microscopic study of the human ovarian surface epithelium: characterization of two cell types. Mol. Hum. Reprod. 6: 645-650.

Hartanti, M.D., Hummitzsch, K., Bonner, W.M., Bastian, N.A., Irving-Rodgers, H.F. and Rodgers, R.J. 2019. Formation of the bovine ovarian surface epithelium during fetal development. J. Histochem. Cytochem. 68: 113-126.

Kumar, S., Gurdial, S. and Nagpal, S. 2008. Scanning electron microscopy of the oviduct of buffalo during follicular phase. Haryana Vet. 47: 32-34.

Pathak, D., Nagpal, S.K. and Singh, G. 2012. Scanning electron microscopy of oviduct of sheep in luteal phase of estrous cycle. Indian Vet. J. 89: 56-58.

Tienthai, P. and Sajjarengpong, K. 2007. A scanning electron microscopic study of oviduct epithelium in culling repeat breeder gilts. Thai J. Vet. Med. 37: 1930.

Tienthai, P., Sajjarengpong, K. and Techakumphu, M. 2009. Light and scanning electron microscopic studies of oviductal epithelium in Thai swamp buffalo (Bubalus bubalis) at the follicular and luteal phases. Reprod. Dom. Anim. 44: 450-455. 